\title{
Traumatic Globe Subluxation and Intracranial Injury Caused by Bicycle Brake Handle
}

\author{
Ceren Poroy, ${ }^{1}$ Cansu Cibik, ${ }^{1}$ and Bulent Yazici ${ }^{1,}$ \\ ${ }^{1}$ Department of Ophthalmology, Uludag University, Bursa, Turkey \\ "Corresponding author: Bulent Yazici, Department of Ophthalmology, Uludag University, Bursa, Turkey. Tel: +90-2242952415, Fax: +90-2444428070, E-mail: \\ byazici@uludag.edu.tr
}

Received 2015 September 25; Accepted 2015 October 05.

\begin{abstract}
Introduction: Penetration of a bicycle brake handle into the orbit is a rare and serious type of trauma. Globe subluxation due to such trauma has not been previously reported.

Case Presentation: A 10-year-old girl presented after falling from a bicycle, which resulted in the handbrake penetrating her right upper eyelid. On examination, the globe was subluxated anteriorly, there was no light perception, and the pupilla was fixed and dilated. Radiologic studies revealed orbitonasal fractures, hemorrhage, emphysema in the orbit and cranium, and rupture of the extraocular muscles. The globe was replaced into the orbit with the help of lateral cantholysis and orbital septotomy. During 22 months of follow-up, the globe remained intact, but total loss of vision, blepharoptosis, and extraocular motility restriction persisted.

Conclusions: This case and previous reports show that bicycle brake handles can cause severe, penetrating orbital and cerebral traumas that can result in vision loss or fatality. Brake handles should be designed to protect bicyclists from such injuries.
\end{abstract}

Keywords: Brain Injuries, Child, Orbital Fracture, Optic Nerve Injuries, Extraocular Muscle

\section{Introduction}

Falling from a bicycle is a common cause of orbitofacial injuries in children, typically resulting in ocular morbidities caused by blunt trauma (1). Penetration of the orbit by a bicycle brake handle is a rare trauma (2). Herein, a patient who experienced globe subluxation and permanent visual loss as a result of such a trauma is presented, with a review of the literature.

\section{Case Presentation}

A 10-year-old girl presented six hours after falling off a bicycle. She had fallen on the handlebar while riding her bicycle without wearing a protective helmet, and the brake handle had penetrated her right upper eyelid. At the time of examination, she was conscious, cooperative, and oriented. The right globe was luxated out of the orbit and suspended on the eyelids (Figure $1 \mathrm{~A}$ and B). There was no light perception in the eye, the pupil was dilated and unresponsive to light stimulation, and diffuse corneal edema and punctate epitheliopathy were present.

Computed tomography showed a fragmented fracture in the greater wing of the sphenoid bone, a linear fracture in the nasal bone, intracerebral and subarachnoid hemorrhage in the temporal lobe, and air in the orbit and cranium. The apical area seemed to be enlarged because of the sphenoidal fracture (Figure 1C). Total rupture of the medial rectus muscle and partial ruptures of the superior and lateral rectus muscles were also reported. Surgery was performed on the same day, and a $15-\mathrm{mm}$ laceration was observed in the upper eyelid. The conjunctiva and anterior Tenon capsule were ruptured circumferentially $4-5 \mathrm{~mm}$ behind the limbus. The medial rectus muscle was ruptured 8 $\mathrm{mm}$ behind its insertion into the globe. The globe could not be repositioned back to the orbit with digital pressure while pulling the upper eyelid anteriorly. Lateral canthotomy, cantholysis, and superior and inferior septotomies were performed to prolapse the orbital fat and reduce the intraorbital pressure. The proximal and distal parts of the medial rectus muscle were located and attached to each other with two 5.0 polyglactin sutures. The globe was then pushed back and replaced into the orbit (Figure 1D). The conjunctiva, eyelid laceration, and lateral canthus were closed with sutures and a temporary blepharorrhaphy was performed. Postoperatively, the patient received systemic prednisolone and antibiotics for one week. During 22 months of follow-up, the globe remained intact, without 
Figure 1. Globe Subluxation and Intracranial Injury Due to Bicycle Brake Handle Penetration Through the Upper Eyelid
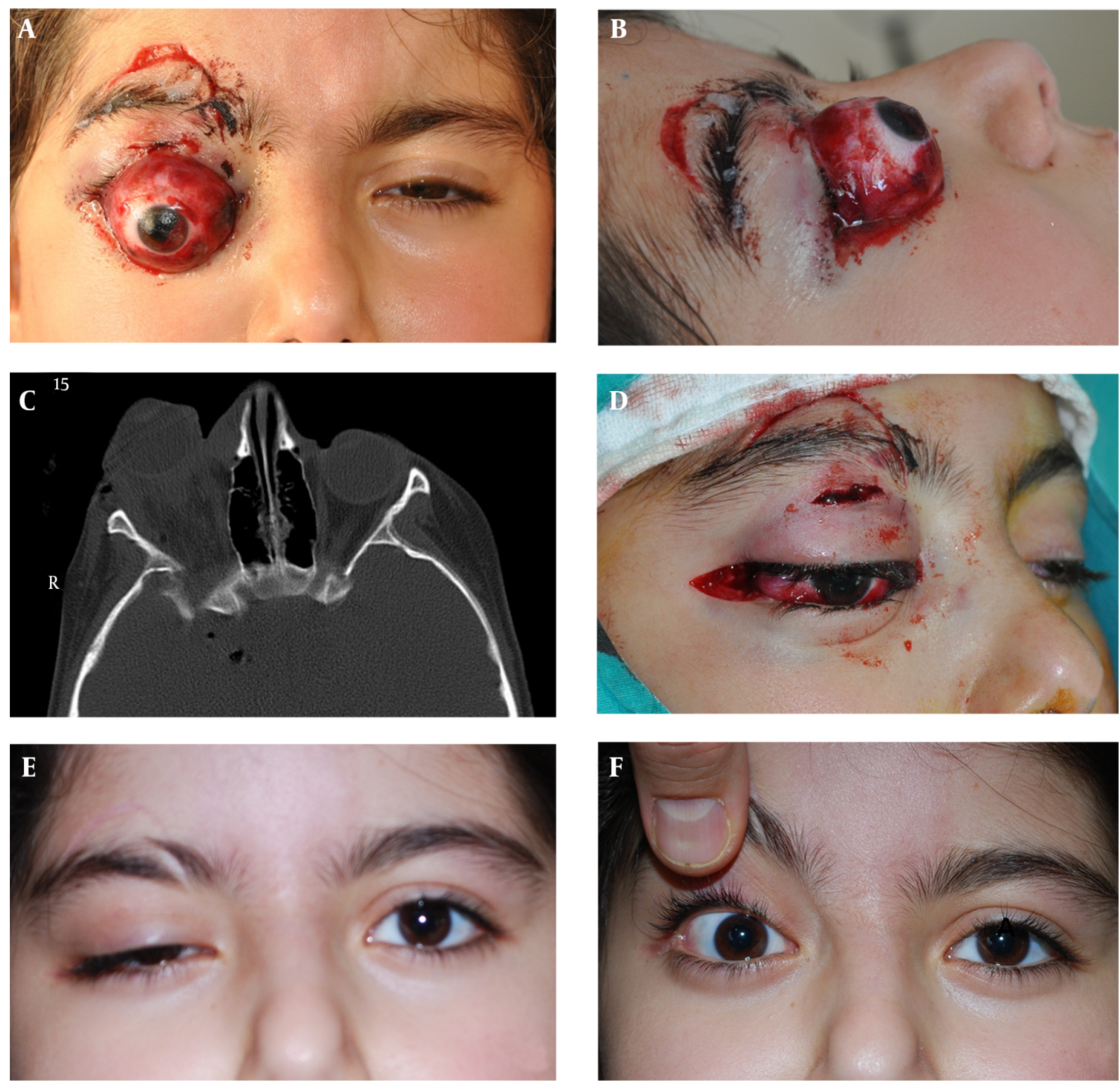

A, Globe subluxation in a 10-year-old child as a result of bicycle handbrake penetration into the orbit; B, Lateral view of the patient; C, Computed tomography showing sphenoidal fracture in the apical orbit, medial rectus rupture, intracranial and intraorbital hemorrhage, and air in association with globe subluxation; D, The globe was repositioned into the orbit after lateral cantholysis and orbital septotomy; E and F, Six months after the trauma, the globe maintained its integrity. Ptosis and eye movement restriction persisted.

light perception, and total optic atrophy developed. Blepharoptosis and eye motility restriction showed slight improvement. The patient was recommended to wear eyeglasses with a ptosis crutch (Figure 1E and F).

\section{Discussion}

Traumatic globe subluxation is a rare condition and is usually related to motor vehicle accidents (3). Brake handles, although rarely, may be a source of orbital injury and mortality among child bicyclists. In the English-language literature, we found seven patients (including the present patient) who were specifically described as having a brake 
handle-related orbital trauma $(2,4-7)$. All of these except for one were children ranging in age from 5 to 10 years (6). In all cases, the orbital injuries were associated with falling from a bicycle, not with a bicycle/motor-vehicle collision. Six patients had transorbital cerebral injuries, five of which required intracranial surgery, and three of which resulted in fatalities (4-6). In one case without cerebral injury, the trauma was relatively trivial and resulted only in an upper eyelid laceration (2). In the previous cases, ocular injuries such as orbital emphysema and hemorrhage, extraocular dysmotility, hyphema, and globe perforation have been reported $(2,4-7)$. In the current case, the cerebral injury did not require surgical treatment, but the orbital trauma was associated with serious morbidities, including globe subluxation, extraocular muscle rupture, total blepharoptosis, and irreversible vision loss.

In their normal positions, the eyelids play a role in preventing dislocation of the globe anteriorly. However, because of its relatively blunt structure, when the brake handle strikes the upper orbit, the intraorbital pressure may increase while the eyelid is pushed back. It is also likely that the brake handle pushes the orbital contents anteriorly, using the apical bone as a fulcrum (8). These processes may result in globe subluxation and extraocular muscle rupture.

Traumatic globe subluxation is a dramatic condition that induces severe distress in the patient and his/her relatives. Enucleation can increase the psychological burden of a patient who has already lost vision (9). The preferred approach to treatment is repositioning of the eyeball into the orbit, if possible. For this, while the upper eyelid is pulled upward, pressing the globe simultaneously backward may be sufficient in many cases (10). In the current case, these noninvasive maneuvers failed, possibly because of increased intraorbital pressure secondary to hemorrhage and edema. After superior and inferior lateral cantholysis and septotomy, the globe could be repositioned easily. Complications such as anterior segment ischemia, phthisis bulbi, and neovascular glaucoma may occur after a subluxated globe is replaced into the orbit $(2,3,8,9)$. None of these complications developed in the current case during 22 months of follow-up. Bicycle brake handles should be designed so that they are not potentially penetrating objects.

\section{Footnote}

Authors' Contribution: All authors contributed to the preparation of this manuscript.

\section{References}

1. Guzel A, Ersoy B, Dogrusoy Y, Kucukugurluoglu Y, Altinel T, Karasalihoglu S. [The evaluation of bicycle accidents that were admitted to a pediatric emergency department]. Ulus Travma Acil Cerrahi Derg. 2006;12(4):299-304. [PubMed: 17029120].

2. Ng JD, Payner TD, Holck DE, Martin RT, Nunery WT. Orbital trauma caused by bicycle hand brakes. Ophthal Plast Reconstr Surg. 2004;20(1):60-3. doi: 10.1097/01.IOP.0000103007.29795.71. [PubMed: 14752313].

3. Lelli Jr GJ, Demirci H, Frueh BR. Avulsion of the optic nerve with luxation of the eye after motor vehicle accident. Ophthal Plast Reconstr Surg. 2007;23(2):158-60. doi: 10.1097/IOP.0b013e31803045b4. [PubMed: 17413639].

4. Ahmad FU, Suri A, Mahapatra AK. Fatal penetrating brainstem injury caused by bicycle brake handle. Pediatr Neurosurg. 2005;41(4):226-8. doi: 10.1159/000086568. [PubMed: 16088262].

5. Chattopadhyay S, Sukul B, Das SK. Fatal transorbital head injury by bicycle brake handle. J Forensic Leg Med. 2009;16(6):352-3. doi: 10.1016/j.jflm.2009.01.010. [PubMed: 19573849].

6. Huiszoon WB, Noe PN, Manten A. Fatal transorbital penetrating intracranial injury caused by a bicycle hand brake. Int J Emerg Med. 2012;5(1):34. doi: 10.1186/1865-1380-5-34. [PubMed: 22989177].

7. Agrawal A, Pratap A, Agrawal CS, Kumar A, Rupakheti S. Transorbital orbitocranial penetrating injury due to bicycle brake handle in a child. Pediatr Neurosurg. 2007;43(6):498-500. doi:10.1159/000108794. [PubMed: 17992039].

8. Morris WR, Osborn FD, Fleming JC. Traumatic evulsion of the globe. Ophthal Plast Reconstr Surg. 2002;18(4):261-7. doi: 10.1097/01.IOP.0000021965.72318.35. [PubMed: 12142758].

9. Kiratli H, Tumer B, Bilgic S. Management of traumatic luxation of the globe. A case report. Acta Ophthalmol Scand. 1999;77(3):340-2. [PubMed: 10406158].

10. Tse DT. A simple maneuver to reposit a subluxed globe. Arch Ophthalmol. 2000;118(3):410-1. [PubMed:10721966]. 